\title{
Primeiro contato com a programação através do Software Scratch: experiência no ensino técnico
}

\author{
Jarles Tarsso Gomes Santos ${ }^{1}$, Jaian Tales Gomes Santos ${ }^{2}$ \\ ${ }^{1}$ Universidade Estadual da Paraíba - Centro de Ciências Exatas e Sociais Aplicadas \\ (Campus VII) - Rua Alfredo Lustosa Cabral, S/N, Bairro Salgadinho, Patos - PB. \\ ${ }^{2}$ Universidade Federal da Paraíba - Centro de Informática, Campus V - Rua dos \\ Escoteiros, $\mathrm{s} / \mathrm{n}^{\circ}$, Mangabeira VII, Distrito Industrial de Mangabeira, João Pessoa - PB. \\ jarlestarsso@gmail.com, jaian_tales@hotmail.com
}

\begin{abstract}
Considering programming as one of the main disciplines in the area of informatics, the present work aims to apply programming techniques with novice students from the technical course in informatics of a high school, in Paraíba, Brazil, using free educational software Scratch, which possesses syntax and interfaces appropriate for those in the first levels of learning in the area. Through the tool, students have developed collective and individual games and animations, by means of strategies proposed by the mediator of activities, aiming to make learning more dynamic, in addition to making programming a pleasant discipline, so that the student has a motivation in reaching more complex levels throughout his studies.
\end{abstract}

Resumo. Por considerar a programação como uma das principais disciplinas na área de informática, o presente trabalho tem como objetivo aplicar técnicas de programação com estudantes iniciantes do Curso Técnico em Informática de uma escola paraibana, usando o software educacional livre Scratch, que possui sintaxe e interfaces apropriadas para aqueles nos primeiros níveis de aprendizado na área. Através da ferramenta, os estudantes desenvolveram jogos e animações coletivas e individuais, por meio de estratégias propostas pelo mediador das atividades, visando tornar o aprendizado mais dinâmico, além de fazer da programação uma disciplina prazerosa, para que o estudante tenha motivação ao se deparar com níveis mais complexos ao longo dos seus estudos.

\section{Introdução}

As Tecnologias Digitais da Informação e Comunicação (TDIC) estão presentes no currículo de grande parte das escolas no Brasil e ao redor do mundo. Hoje é cada vez mais difícil encontrar escolas que não dispõe de ao menos um computador ou ferramenta digital disponível para uso em sala de aula.

É possível atribuir o uso das TDIC na educação à necessidade que os alunos possuem em desenvolver habilidades acerca destas ferramentas, tendo em vista que hoje o mercado de trabalho exige ao menos um conhecimento mínimo acerca de alguns conceitos, independente da carreira profissional escolhida pelo aluno (von Wangenheim, Nunes e dos Santos 2014). 
VI Congresso Brasileiro de Informática na Educação (CBIE 2017)

Anais do XXIII Workshop de Informática na Escola (WIE 2017)

Ao inserir TDIC na educação, diversas vertentes são abertas, possibilitando o estudo de várias áreas da informática. Dentre as possibilidades ofertadas, é possível destacar disciplinas voltadas para o estudo da lógica de programação.

Uma linguagem de programação se caracteriza como um método de comunicação com o computador, usado para transformar a linguagem humana em uma linguagem que a máquina possa entender, na qual realizamos através de instruções que são informadas à máquina, e em seguida interpretadas e executadas por ela. Para Scaico et al. (2013) o aprendizado da programação deve partir desde o ensino regular, pois assim o aluno poderá logo cedo desenvolver habilidades para resolução de problemas e facilidade em utilizar tecnologias, que são comumente exigidas em nosso cotidiano (Scaico et al. 2013).

Muitos alunos já possuem grande facilidade em utilizar tecnologias e os que não os fazem, possuem grande interesse em trabalhar com ferramentas consideradas inovadoras. Isso evidencia o quão atrativas são as tecnologias, que são utilizadas diariamente no entretenimento dos alunos. A partir dessa conjectura, é possível inserilas na educação, de modo que os alunos não sejam apenas meros consumidores da tecnologia, mas consigam explorá-las afundo, tornando-se também produtores dela (Silva e Carvalho 2016).

Apesar da sua imensa contribuição, disciplinas que envolvem programação são consideradas as mais difíceis da área, por possuírem um grau de dificuldade elevado. Essas disciplinas são responsáveis pelo maior índice de reprovações em cursos de nível técnico e superior da área. É possível atribuir essa fatalidade ao modo como são aplicadas as disciplinas, sem uso de materiais diferenciados, fazendo com que o aprendizado não seja intuitivo (Oliveira, Rodrigues e Queiroga 2016).

Por esse motivo, diversos projetos são desenvolvidos, com o intuito de facilitar a aprendizagem da programação nas instituições de ensino. O Scratch, por exemplo, é um projeto desenvolvido por pesquisadores do MIT Media Lab, disponibilizado como software livre, para qualquer pessoa interessada em fazer seu uso. O Scratch torna possível desenvolver jogos e animações interativas, que podem ser partilhadas com outras pessoas através da plataforma da aplicação (Scratch, 2017).

O Scratch utiliza a programação em blocos, que vem sendo muita utilizada para ajudar estudantes nos primeiros níveis de conhecimento acerca da programação. Boa parte dos softwares desenvolvidos teve como base a Linguagem Logo, proposta por Seymour Papert, desenvolvedor da ideologia construcionista, onde o autor afirma que o aluno constrói o seu conhecimento, a partir da sua interação com o computador, à medida que o aluno diz o que deve ser feito. Para Papert (1986) é importante criar situações para que os aprendizes se engajem em atividades que alimentem esse processo construtivo, fazendo com que a aprendizagem se torne significativa. Em relação às TDIC, conclui que tecnologia não é a solução, mas uma ferramenta para auxiliar o professor. Portanto, não é fator principal para uma boa educação, mas também, a falta dela implica numa má educação (Papert 2001).

Partindo dessa conjectura, este trabalho propõe o desenvolvimento de projetos utilizando a linguagem de programação Scratch, antes e durante a realização do evento Scratch Day, que acontece anualmente em vários países. Participaram alunos matriculados no primeiro ano do Curso Técnico em Informática, em uma escola de Ensino Médio. Os métodos usados para a realização das atividades foram através de 
aulas laboratoriais práticas, objetivando dar início a prática de programação através de ferramentas simples, para que o aprendizado se torne mais fácil ao se depararem com métodos mais complexos no decorrer do curso.

\section{Scratch Day}

O Scratch Day é um evento que acontece anualmente ao redor do mundo, no qual qualquer pessoa pode se inscrever como organizador, para realizar as atividades propostas pela ideologia do evento. As atividades realizadas servem para inspirar pessoas a desenvolverem e compartilharem projetos criativos, seja iniciante ou experiente na área de programação (Scratch Day 2017).

O próprio evento busca facilitar o processo, através de dicas essenciais para a realização das atividades e consequentemente do aprendizado por parte dos participantes. É sugerido deixar que os participantes busquem as respostas para eventuais problemas, de modo que possam fazer suas próprias escolhas. O mediador da atividade deve ser apenas um facilitador do processo. Outras sugestões são tornar as atividades mais interessantes, através do uso de conceitos que sejam importantes para quem desenvolve, pois torna o processo mais significativo.

\section{Scratch como auxílio no aprendizado da programação}

O Scratch possui como objetivo ajudar os jovens a pensarem de forma criativa, enquanto raciocinam para resolver problemas através da linguagem de programação, por considerar que essa capacidade cognitiva é indispensável para a sociedade atual (Scratch 2017).

A Linguagem Scratch pode ser acessada de diversas maneiras. É possível fazer a instalação do software em um computador, para usá-lo no momento mais oportuno ou por meio de um dispositivo mobile, através do Scratch Jr. Outra opção é o acesso diretamente no site do MIT (scratch.mit.edu), necessitando apenas de uma conexão com internet.

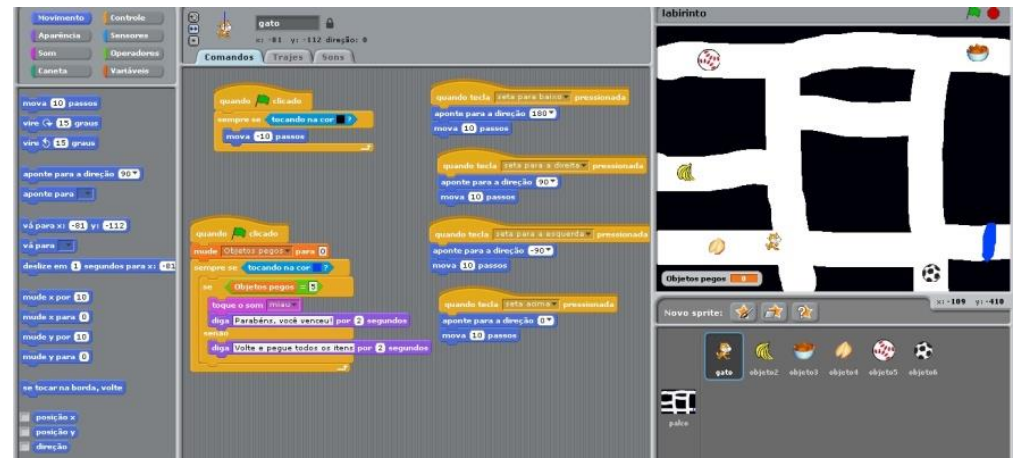

Figura 1. Scratch acessado através de instalação. 
VI Congresso Brasileiro de Informática na Educação (CBIE 2017)

Anais do XXIII Workshop de Informática na Escola (WIE 2017)

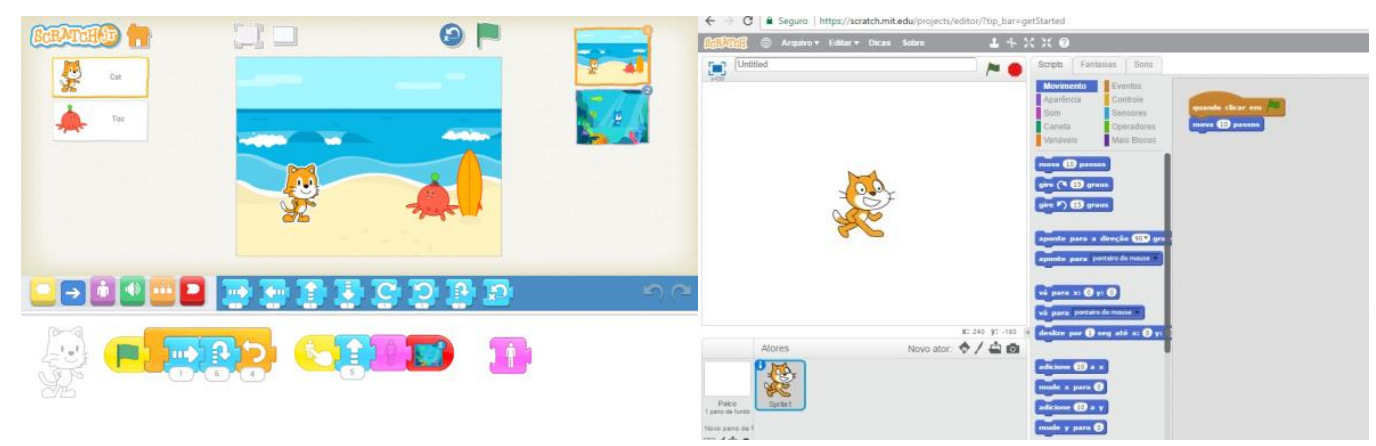

Figura 2. a) Scratch acessado pela internet. b) Scratch acessado por mobile.

A Linguagem Scratch se diferencia de outras por sua fácil manipulação, através da programação orientada a objetos, usando blocos de arrastar e soltar, que podem ser ligados, formando blocos maiores para executar as funções designadas a cada um deles. Esse modelo de programação possui uma interface mais agradável, que facilita o aprendizado do aluno, pois eles podem programar, mesmo não tendo um prévio conhecimento acerca da lógica de programação, realizando projetos de forma rápida (Ramos e Teixeira 2015). Essa característica diferencia o Scratch das linguagens convencionais, que exigem que aluno tenha o conhecimento prévio da sintaxe antes de iniciar a programação. Através dos blocos, o aluno já observa a funcionalidade de cada elemento da programação, evitando maiores erros de sintaxe.

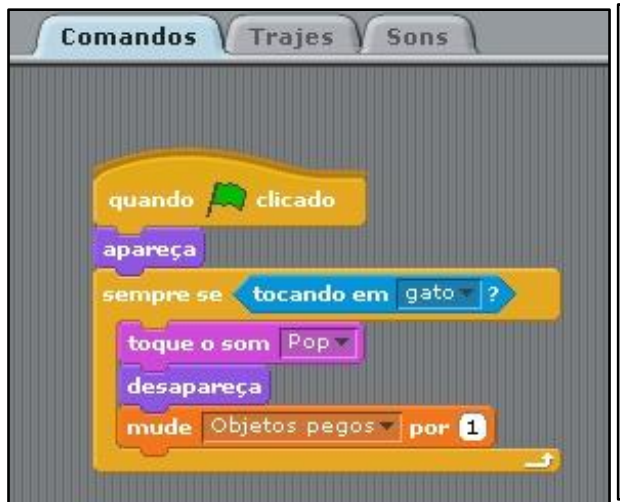

\begin{tabular}{l|l|} 
parafrente 50 & paradireita 90 \\
paraesquerda 90 & parafrente 70 \\
parafrente 10 & paradireita 90 \\
paradireita 135 & parafrente 40 \\
parafrente 100 & paraesquerda 90 \\
paradireita 90 & parafrente 30 \\
parafrente 100 & paraesquerda 90 \\
paradireita 135 & parafrente 40 \\
parafrente 10 & paradireita 90 \\
paraesquerda 90 & parafrente 21 \\
parafrente 50 & paradireita 90
\end{tabular}

Figura 3. a) Sintaxe do Scratch. b) Sintaxe da linguagem Logo.

Resnik (2014) também defende a ideia de que os conhecimentos aprendidos através do Scratch são fundamentais para os alunos quando vierem a enfrentar o mundo fora da escola. Para Resnik no momento em que são desenvolvidos projetos através do Scratch, muitas habilidades críticas são desenvolvidas para um futuro promissor, dentre as quais se encontram a maneira de pensar criativamente, a comunicação objetiva, capacidade de analisar de forma sistemática, colaboração, capacidade de aprendizado contínuo e uso fluente das tecnologias (Resnik 2007). Através da ferramenta Scratch e da teoria constricionista, ele aborda o que chama de Quatros P's da aprendizagem criativa, que podem ser estimulados através da programação com esta ferramenta:

Projetos (Projects): quando se trabalha ativamente em projetos com significado, novas ideias surgem, melhorando o aprendizado.

Pares (Peers): as atividades que envolvam interação social ajudam no relacionamento das pessoas, no momento em que elas se tornam colaborativas. 
VI Congresso Brasileiro de Informática na Educação (CBIE 2017)

Anais do XXIII Workshop de Informática na Escola (WIE 2017)

Paixão (Passion): ao desenvolver projetos com significado, a pessoa os desenvolve com mais interesse, persistindo mesmo havendo dificuldades.

Jogar (Play). A aprendizagem se torna divertida, no momento em que se executam os trabalhos realizados.

Hoje o Scratch é usado em mais de 150 países, por isso dispõe de mais de 40 idiomas, contribuindo para o aprendizado de estudantes nos níveis de educação básica e superior. A ferramenta pode auxiliar não só para o aprendizado de programação, mas de disciplinas como matemática, ciências, português, entre outras (Scratch 2017). Para isso, basta que o professor planeje a atividade adequada para sua disciplina.

\section{Metodologia}

As atividades realizadas neste estudo foram desenvolvidas através da leitura das fontes bibliográficas que serviram de base para a sua construção, de tal forma que a escolha foi pela divisão em três etapas: (1) apresentação do software, (2) desenvolvimento de projetos com base nas ideias sugeridas pelo mediador da atividade e (3) projetos autônomos, durante o Scratch Day. A turma selecionada para realizar as atividades foi a do $1^{\circ}$ ano do Curso Técnico em Informática da escola, que já possuem certo interesse e conhecimento acerca da área da computação. Todas as atividades aconteceram no laboratório de informática da escola, que dispõe do essencial para as atividades em questão.

A avaliação foi feita por meio de observações dos projetos desenvolvidos, dando liberdade para que os alunos pudessem errar e encontrar soluções para seus erros, sendo a função do mediador apenas auxiliar o aluno na busca por soluções e não respostas prontas. A observação é importante, pois o mediador pode atuar como um observador e participar ativamente do processo, no qual se torna um observadorouvinte, que facilita o acesso as informações (Silva et al 2010).

O início dos trabalhos aconteceu com a apresentação de como ocorre o processo de programação de um software, bem como é feito a leitura dos algoritmos pelo computador, além de expor a importância da programação na área de computação. Feito isso, o software Scratch foi exibido, com a apresentação da sua estrutura em blocos, explorando cada parte de maneira individual, de modo que ao fim, todos os blocos fossem utilizados. Algumas animações foram criadas, fazendo com que objetos se movessem, sumissem e realizassem inúmeras outras ações, para que as estruturas da sintaxe do Scratch fossem entendidas com clareza.

Em outro momento, foram desenvolvidos animações e jogos mais sofisticados, que foram selecionadas pelo mediador das atividades, por entender que trabalham elementos importantes da lógica de programação, como as estruturas de repetição e variáveis. A proposta foi criar uma empresa, em que os estudantes eram responsáveis pelo desenvolvimento de softwares e o mediador, um auxiliar, no qual dizia o que devia ser feito e através de discussões, os estudantes informavam os passos a serem seguidos.

Portanto, foi sugerido que um cliente desejava criar um jogo para ajudar crianças a treinar operações matemáticas de soma. Junto aos estudantes, foi sugerido o desenvolvimento de um jogo que tivesse características infantis, para que fosse agradável ao usuário. Ficou então decidido usar o tema Pokémon, aproveitando a febre do jogo produzido pela empresa Niantic, intitulado Pokémon GO. A série de jogos 
eletrônicos existentes sobre o tema possui como característica realizar a captura de seres denominados Pokémon. A franquia é de propriedade da Nintendo ${ }^{\circledR}$ e The Pokémon Company. O jogo produzido pelos estudantes da escola foi então batizado de Pokesoma. Antes de iniciar a implementação do jogo, foi mostrado àquele que serviu de inspiração, explorando suas funcionalidades para tentar replicar partes desejadas.

A implementação foi iniciada seguindo etapas, ao observar como acontecia no jogo fonte de inspiração. Por exemplo, os alunos perceberam que assim que o objeto de captura, intitulado Pokebola encostava-se ao Pokémon, ele desaparecia. Logo, decidiram que o código deveria ficar como o ilustrado abaixo:

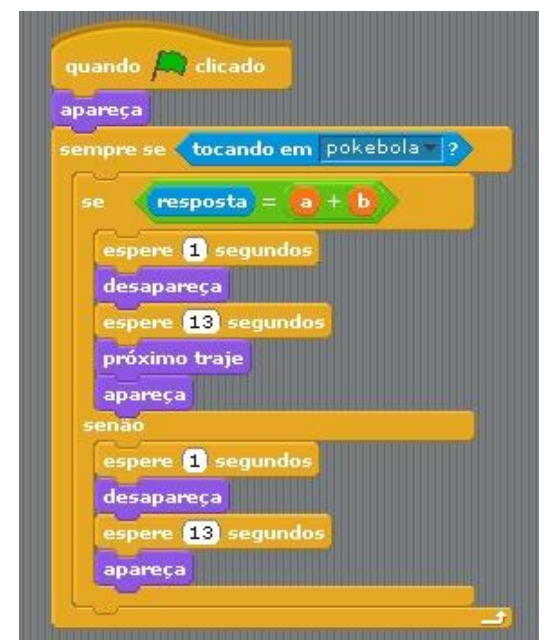

Figura 4. Exemplo de código usado no jogo Pokesoma.

A partir disso, as demais funcionalidades do jogo foram sendo seguidas, diferindo apenas ao ser necessário inserir as operações matemáticas. Para isso foi preciso o uso de variáveis, de modo que eram sorteados números entre 1 e 10 para formar uma soma entre dois números. Portanto, ao iniciar o jogo, um Pokémon era exibido na tela, juntamente com uma operação matemática. Através das estruturas de condição, o jogo foi implementado para capturar o Pokémon caso o jogador acerte ou deixa-lo escapar e sugerir uma nova tentativa, caso a resposta estiver errada.

A terceira etapa dos trabalhos ocorreu em outro momento, com a realização do evento Scratch Day. Como propõe as sugestões de organização, nesse dia os estudantes tiveram acesso livre ao laboratório, para desenvolver quaisquer projetos que tivessem em mente, sendo o mediador apenas um facilitador, com sugestões de aperfeiçoamento dos projetos ali realizados.

\section{Resultados e Discussão}

O principal objeto ao final das atividades foi para que os alunos participantes adquirissem o conhecimento necessário acerca da lógica de programação, para que sirva de apoio a estudos mais avançados da área, pois a programação favorece a capacidade de raciocínio lógico e letramento digital, no momento em que os alunos passam a ser desenvolvedores (Shimohara; Sobreira e Ito 2016). Além disso, é importante destacar a contribuição a outras disciplinas que compõem o currículo escolar, com ênfase na leitura, escrita e aritmética (Wing 2006). 
Foi possível perceber através da primeira etapa do trabalho, na qual os estudantes estavam tendo o primeiro contato com a ferramenta Scratch, o quão favorável ela é no fator social do aluno, pois permite que um grupo possa se auxiliar em momentos de dificuldade individual. Esse fato ficou perceptível no momento em que surgiram dúvidas partindo de algum estudante, visto que em determinados momentos o papel do mediador foi dispensado, pois os demais estudantes conseguiam auxiliar àquele com dificuldades.

Ainda no primeiro encontro, foi abordado o conceito de plano cartesiano, visto que a ferramenta Scratch utiliza valores para $\mathrm{x}$ e y no posicionamento dos objetos em relação ao palco do jogo ou animação. Outros conceitos matemáticos são o de rotação, dado por alguns blocos em graus e a parte destinada aos operadores matemáticos, presentes em qualquer linguagem de programação. Portanto, é uma evidência da capacidade que a programação possui em relacionar o estudo com outras áreas da educação.

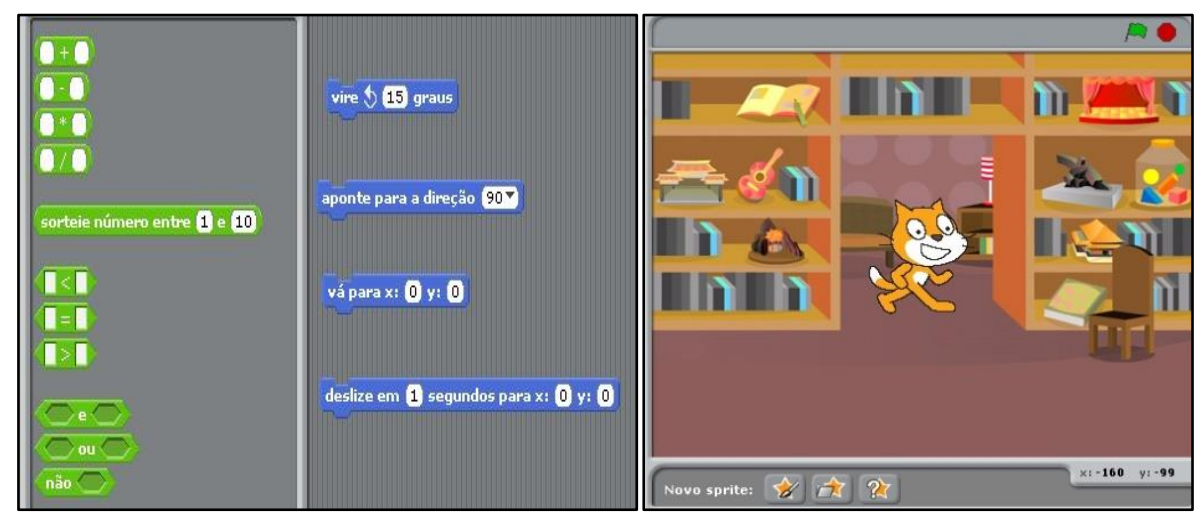

Figura 5. a) Blocos matemáticos. b) Coordenadas no canto inferior direito.

Os acontecimentos do segundo encontro focaram na autonomia do estudante, pois atribuiu a ele uma responsabilidade, por fantasiar uma empresa, na qual há objetivos a serem cumpridos. Também foi exigido que o estudante tivesse autonomia para buscar soluções para os problemas, que eventualmente surgiram.

Os conceitos acerca da matemática foram novamente exigidos, pois o próprio objetivo do jogo desenvolvido é a resolução de operações. Nesse caso o estudante foi colocado não mais na função de receptor da informação, mas de algo que podemos chamar de receptor-preceptor. O primeiro por continuar aprendendo conceitos de programação e o segundo por estar desenvolvendo algo que irá exigir que o futuro usuário torne-se aprendiz através dos conceitos ofertados pelo jogo. 
VI Congresso Brasileiro de Informática na Educação (CBIE 2017)

Anais do XXIII Workshop de Informática na Escola (WIE 2017)

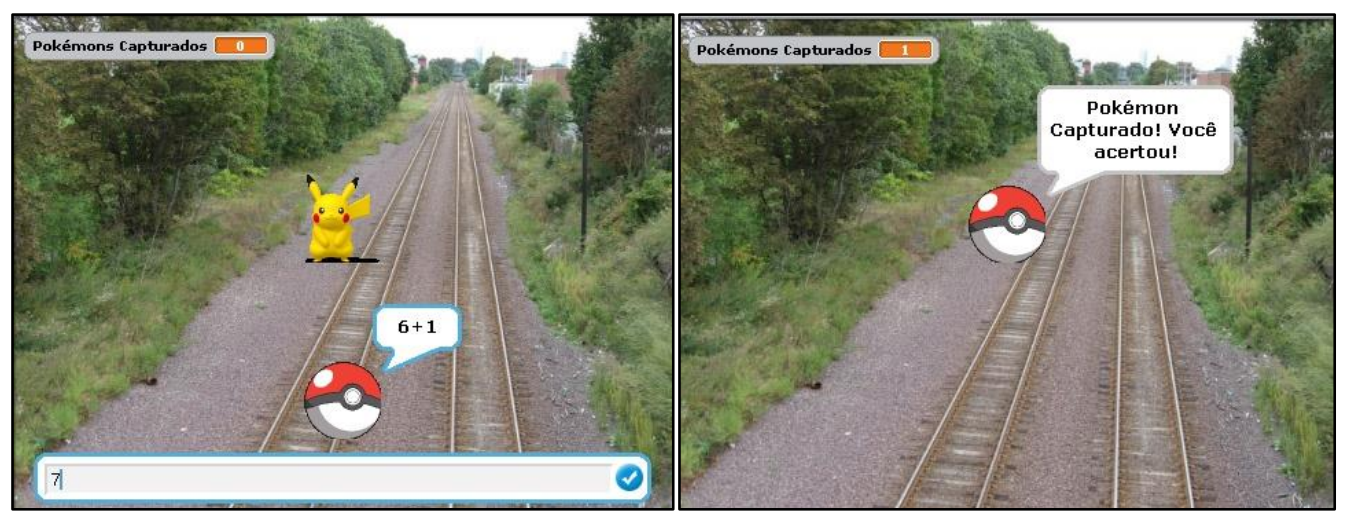

Figura 6. a) Jogo Pokesoma b) Tela ao acertar operação.

Por se tratar de adolescentes, ficou evidente que a ideia de um jogo com tema conhecido por eles não viria a tornar o aprendizado mais interessante apenas para a criança que viesse a aprender operações matemáticas com ele. Os próprios desenvolvedores aumentaram o seu interesse devido ao fato de possuir elementos já conhecidos por eles no cotidiano. Afinal, o tema proposto para o jogo é de conhecimento mundial.

Com o passar do tempo, os próprios estudantes sugeriram outros temas, questionando se poderiam fazer acerca dele. Fica claro o quão motivador a atividade se tornou, por almejarem desenvolver novos projetos no futuro. Outro exemplo foram sugestões de melhoria para o jogo, no qual estudantes informaram ser possível incluir operações mais complexas e com operadores diferentes, como subtração, multiplicação e divisão, além de alterações no cenário, como a inclusão de um menu e a divisão do jogo em níveis de dificuldade.

O último encontro aconteceu no dia programado para ocorrer o Scratch Day. A escola em questão realiza o evento desde o ano de 2016, quando recebeu o Curso Técnico em Informática. Como já mencionado, o Scratch Day é um evento voltado para a prática da programação por parte dos estudantes, de modo que possam desenvolver ideias e partilha-las. Portanto, esse foi um dia no qual todos puderam realizar aqueles projetos que vieram alimentando ao longo dos demais encontros, quando foi exigido seguir o planejado pelo mediador.

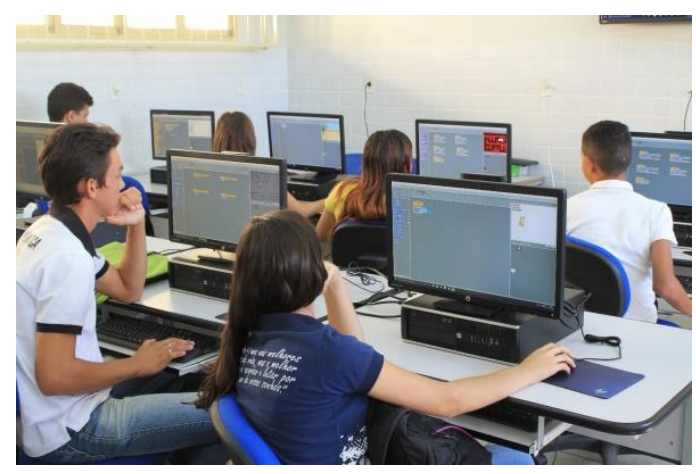

Figura 7. Atividades do Scratch Day.

Ficou evidente a facilidade de uns e dificuldade de outros, que pode ser atribuído ao interesse de cada estudante. Mas vale salientar que o processo de aprendizagem é pessoal, e pode ocorrer pela observação, interação ou o 
VI Congresso Brasileiro de Informática na Educação (CBIE 2017)

Anais do XXIII Workshop de Informática na Escola (WIE 2017)

compartilhamento de experiências (Moran 2013). Portanto, cada estudante possui sua forma de aprender, devendo ser evitado julgamentos precipitados.

\section{Conclusão e Trabalhos Futuros}

Diante do que foi discutido, é possível perceber o quão motivador o aprendizado da programação pode ser para o estudante, desde que sejam trabalhados temas do seu cotidiano, usando artefatos que tenham significado para ele. Dessa maneira, as atividades fogem do habitual, de modo que o estudante não verá o estudo como uma obrigação monótona, como comumente ocorre, mas poderá sentir mais entusiasmo na realização dele. Para isso, é indispensável que o mediador da atividade tenha conhecimento dos interesses pessoais da turma, para que assim possa propor temáticas relevantes.

Um fato importante a ser comentado é a evasão causada por disciplinas que envolvem programação, por possuir um alto nível de dificuldade. Mesmo com todos os estudantes cumprindo suas obrigações, foi possível perceber durante a realização do Scratch Day que alguns almejaram projetos grandes, mas o que outrora fora entusiasmante, acarretou na desistência do projeto devido aos inúmeros empecilhos que surgiram. Portanto cabe ao mediador buscar soluções para não permitir que isso ocorra, mesmo que emane mais tempo. Nos momentos em que esse fato ocorreu, o aconselhável foi que o aluno realizasse a implementação de ao menos parte do projeto mencionado, para que posteriormente fosse melhorado.

A partir deste projeto, foi constatada a possibilidade que o Scratch oferece de aguçar a curiosidade do estudante para desenvolver projetos usando uma linguagem de programação, desde que sejam usadas as estratégias corretas. Cabe ainda aguardar que outras disciplinas de programação sejam ofertadas aos estudantes participantes, como conceitos de linguagens como $C, C++$, Python ou Java, por exemplo, para que futuramente seja observado se os conceitos aprendidos com o Scratch podem servir de apoio a linguagens de programação mais difíceis, que irão exigir maior esforço por parte do estudante.

Outra vertente aberta por este estudo é o possível uso do jogo Pokesoma por estudantes das séries iniciais do ensino básico, que estão começando a aprender conceitos sobre operações matemáticas, em particular a soma. Através da aplicação do jogo, pode ser observado o seu efeito sobre a aprendizagem desse estudante. Portanto, o Pokesoma será usado em momento oportuno, onde serão exibidos os seus resultados em outro projeto a ser realizado.

\section{Referências}

Moran, J. (2013). Novas Tecnologias e Mediação Pedagógica, Editora Papirus, $21^{\text {a }}$ Ed.

Oliveira, M. V., Rodrigues, L. C. e Queiroga, A. P. G. (2016). Material didático lúdico: uso da ferramenta Scratch para auxílio no aprendizado de lógica da programação. In: Anais do Wie. Páginas 359-368.

Papert, S. (1986). Constructionism: A new opportunity for elementary science education. Cambridge: Massachusetts Institute of Technology, Media Laboratory, Epistemology and Learning Group. 
VI Congresso Brasileiro de Informática na Educação (CBIE 2017)

Anais do XXIII Workshop de Informática na Escola (WIE 2017)

Papert, S. (2001). Education for the knowledge society: a Russia-oriented perspective on technology and school. IITE Newsletter. Unesco.

Ramos, F. O. e Teixeira, L. S. (2015). Significação da Aprendizagem Através do Pensamento Computacional no Ensino Médio: uma Experiência com Scratch. In: Anais do Wie. Páginas 217-226.

Resnick, M. (2007). Learning from Scratch, Microsoft Faculty Connection.

Resnick, M. (2014). Give P'sa chance: Projects, peers, passion, play. In Constructionism and creativity: Proceedings of the Third International Constructionism Conference. Páginas 13-20.

Scaico, P. D., de Lima, A. A., Azevedo, S., da Silva, J. B. B., Raposo, E. H., Alencar, Y., Mendes, J. P., Scaico, A., et al. (2013). "Ensino de programação no ensino médio: Uma abordagem orientada ao design com a linguagem scratch." Revista Brasileira de Informática na Educação, v. 21, n.02, páginas 92-103.

Scratch. (2017). Acerca. Disponivel em: < https://scratch.mit.edu/>. Acesso em: 12 Junho 2017.

Scratch Day. (2017). "Scratch Day is a global network of events that celebrate Scratch". Disponível em < https://day.scratch.mit.edu/>. Acesso em 12 junho 2017.

Shimohara, C., Sobreira, E. S. R. e Ito, O. (2016). Potencializando a programação de jogos digitais de matemática através do Scratch e da avaliação Game Flow. In: Anais do Wie. Páginas 436-445.

Silva, M. O. L.. et al. (2010) Etnografia e Pesquisa Qualitativa: Apontamentos Sobre um Caminho Metodológico de Investigação. In: VI Encontro de Pesquisa em Educação.

Silva, L. R. e Carvalho, D.B.F. (2016). Saberes D’Avó: Uma Abordagem para o Ensino de Programação no Ensino Médio. In: Anais do Wie. Páginas 1-10.

von Wangenheim, C. G., Nunes, V. R. e dos Santos, G. D. (2014). "Ensino de Computação com SCRATCH no Ensino Fundamental - Um Estudo de Caso". Revista Brasileira de Informática na Educação, v. 22, n. 3, páginas 115-125.

Wing, J. M. (2006). "Computational Thinking”. Communications of the ACM, v. 49, n. 3 , páginas 33-35. 